\title{
Positive Psychology
}

\author{
Dr. Shaifali Agarwal \\ Assistant Professor, Dept. of Psychology, \\ G. D. H. G. College, Moradabad \\ Email: akshat02agarwal@gmail.com
}

\begin{abstract}
Positve Psychology is the study of positive aspects of life which makes life worthy. It focuses on both individual as well as societial level. Positive psychology began as a branch of psychology in 1998 when Martin Seligman chose it as a theme during his presidentship in American Psychological Association. It is a reaction against behaviorism, which have focused on "mental illness It is also against negative behaviour. It emphasise on happiness and positivity thus creates backbone which is called Positive Psychology.
\end{abstract}

Key words- psychology, societial, behaviourism
Reference to this paper should be made as follows:

Received: 20.08.2020

Approved: 28.09.2020

Dr. Shaifali Agarwal

Positive Psychology

Article No. 22

RJPSS Sept. 2020,

Vol. XLV No. 2,

pp. 191-200

Online available at:

https://anubooks.com/rjpss2020-vol-xlv-no-2/

https://doi.org/10.31995/

rjpss.2020.v45i01.022 


\section{History}

Positive psychologists have suggested a number of ways in which individual happiness may be fostered. Social ties with a spouse, family, friends and wider networks through work, clubs or social organisations are of particular importance. Yoga and meditation is best way to remain happy. There are certain phases in life when happiness reaches its peak and falls due to certain reasons of life. Martin Seligman and Mihaly Csikszentmihalyi define positive psychology as "... the scientific study of positive human functioning and flourishing on multiple levels that include the biological, personal, relational, institutional, cultural, and global dimensions of life

It is concerned with good living according to what holds the greatest value in life - the factors that contribute the most to a well-lived and fulfilling life. Positive Psychologists agree to live a understanding and meaningful life in order to live a happy life ". Martin Seligman referred to "the good life" as "using your signature strengths every day to produce authentic happiness and abundant gratification".

Positive psychology does not replace old and traditional areas of psychology rather it is in addition to it. Study of Positive Psychology helps an individual to balance negative emotion and lead a positive life . Positive psychology has also fostered positive self -esteem in an individual.

The basic goal of positive psychology is that humans think more about future than past . A change in our thinking to time can dramatically affect how we think about the nature of happiness. Seligman identified other possible goals: families and schools that allow children to grow, workplaces that aim for satisfaction and high productivity, and teaching others about positive psychology.

Those who practice positive psychology attempt psychological interventions that develops positive attitudes toward one's subjective experiences, individual traits, and life events The goal is to reduce negative thoughts that arises in our mind . Instead we should focus on positive thoughts of life. Positive psychologists seek to encourage acceptance of past and future events, and a sense of contentment and well-being in the present.

\section{Three pillars of positive psychology}

Positive Psychology has three core pillars : positive experiences, positive individual traits, and positive institutions. Understanding positive emotions deals with the forgetting about past and future events and live in present . Understanding positive individual traits involves studying strength, capability, ability to work etc.Understanding positive institutions deals the study of the strengths that focus on communities such as justice, confidence etc. 
RJPSS Sept. 2020 Vol. XLV No.2, ISSN: (P)0258-1701 (e)2454-3403 Impact Factor: 7.717

https://doi.org/10.31995/rjpss.2020.v45i01.023

As a field, positive psychology spends much of its time thinking about topics like character strengths, optimism, life satisfaction, happiness, well-being, gratitude, compassion (as well as self-compassion), self-esteem and self-confidence, hope, and elevation.

These topics help people to lead positive life and a happy life.

\section{Three levels of positive psychology}

Positive Psychology is concerned with three levels-

1) the subjective level

2) the individual level

3) the group level.

1. The subjective level deals the study of positive experiences such as joy, well-being, satisfaction, contentment, happiness, optimism and flow. This level is only limited to feeling good .

2. The next level deals with learning about personal qualities thata person should develop, through studying human strengths and virtues, future-mindedness, capacity for love, courage, perseverance, forgiveness, originality, wisdom, interpersonal skills and giftedness.

3. Finally, at the group or community level, the aim is to deal with factors required as citizenship like social responsibility etc.

\section{Importance of Positive psychology}

The main function of positive psychology is to change the vision of life .

There is use of many techniques, exercises, and even entire programs based on positive psychology because a relatively small change in one's vision can lead to a positive life. Presence of a little bit of gratitude into your life is a simple action that can give you positivity in our life.

Of course, no respected positive psychologist would tell you to think about, act out, and focus on ONLY the positive in life-balance is important. Positive psychology was not established to replace traditional psychology, but to complement it with a positive bias that's just as strong as psychology's negative bias over the last several decades.

\section{Studies and Research}

Positive psychology develops an insight vision of positivity in our life.It tells us ways in which we can approach towards positive outlook of our life . For example, each of these findings gives us a concrete idea for improving our own quality of life: 
1. People overestimate the impact of money on their happiness by quite a lot. It does have some influence, but not nearly as much as we might think, so focusing less on attaining wealth will likely make you happier (Aknin, Norton, \& Dunn, 2009);

2. Spending money on experiences provides a bigger boost to happiness than spending money on material possessions (Howell \& Hill, 2009);

3. Gratitude is a big contributor to happiness in life, suggesting that the more we cultivate gratitude, the happier we will be (Seligman, Steen, Park, \& Peterson, 2005);

4. Oxytocin may provoke greater trust, empathy, and morality in humans, meaning that giving hugs or other shows of physical affection may give you a big boost to your overall well-being (and the well-being of others; Barraza \& Zak, 2009);

5. Those who intentionally cultivate a positive mood to match the outward emotion they need to display (i.e., in emotional labor) benefit by more genuinely experiencing the positive mood. In other words, "putting on a happy face" won't necessarily make you feel happier, but putting in a little bit of effort likely will (Scott \& Barnes, 2011);

6. Happiness is contagious; those with happy friends and significant others are more likely to be happy in the future (Fowler \& Christakis, 2008);

7. People who perform acts of kindness towards others not only get a boost in well-being, they are also more accepted by their peers (Layous, Nelson, Oberle, Schonert-Reichl, \&Lyubomirsky, 2012);

8. Volunteering time to a cause you believe in improves your well-being and life satisfaction and may even reduce symptoms of depression (Jenkinson et al., 2013);

9. Spending money on other people results in greater happiness for the giver (Dunn, Aknin, \& Norton, 2008

Through various studies it is found that positive psychology is also helpful in building a good carrier:

1. Positivity improves job performance

2. It is also required by a good leader. If leader is positive then he/she can enhance positivity in entire team. 
RJPSS Sept. 2020 Vol. XLV No.2, ISSN: (P)0258-1701 (e)2454-3403 Impact Factor: 7.717

https://doi.org/10.31995/rjpss.2020.v45i01.023

3. Small, simple actions can have a big impact on positivity in life.

People think that only success is key for happiness. Inspite thinking positive emotions also makes us happy and infact increases chance of success.

However, don't assume that refusing negative emotions to enter into your mind will help you reach success. An important finding from positive psychology research is that forcing people who are not willing to think positive can cause more harm and can also be detrimental to health.

The another most important benefit of positive psychology is to provide an idea about what a good life is and how to lead it.

Renowned positive psychologist Roy F. Baumeister and colleagues took on the challenge of determining what makes a good life, and they found some interesting findings that you can apply to your own life (2013). Their research clearly indicates that thinking only about positive emotions can not only help in leading a positive life that we want .

Some of their more specific findings included the following:

1. Focusing towards our goal can increase happiness but we cannot get a deeper sense of happiness until we achieve the goal. There is not any substitute of it.

2. Happiness is related to present, rooted in the moment, while meaningfulness is linked more with past and future and how they are connected to present .This finding suggests that we can think about present to increase happiness but to find meaning we have to think about past as well as future.

3. "Givers" experience more meaning, while "takers" experience more happiness; if you find yourself lacking in meaning, try giving back to others, but if you are lacking in happiness, try being accepting of others' generosity to give yourself a boost.

4. Worry, stress, and anxiety are experienced by those people who live life for meaningfulness and not for happiness. This clearly indicates that a little negative emotions in life is required for meaningfulness.

5. An intention to experience a sense of strong personal identity are linked to meaning, but not to happiness; If we want to experience meaningfulness we have to experience authenticity.

Findings such as these have given rise to, and are driven by, a number of interesting theories that pepper the positive psychology literature. 


\section{Theories related to positive psychology}

There is no accepted "gold standard" theory in positive psychology, however the work of Seligman is regularly quoted So too the work of Csikszentmihalyi and older models of well-being, such as Carol Ryff's Six-factor Model of Psychological Well-being and Diener's tripartite model of subjective well-being.

Initial theory: three paths to happiness

In Authentic Happiness (2002) Seligman proposed three kinds of a happy life which can be investigated:

1. Pleasant life: Research into the Pleasant Life, or the "life of enjoyment", examines how people optimally experience, forecast, and savor the positive feelings and emotions that are part of normal and healthy living (e.g., relationships, hobbies, interests, entertainment, etc.). Despite the attention given, Martin Seligman says this most transient element of happiness may be the least important.

2. Good Life: Investigation of the beneficial effects of immersion, absorption, and flow, felt by individuals when optimally engaged with their primary activities, is the study of the Good Life, or the "life of engagement". Flow is experienced when there is a positive match between a person's strength and their current task, i.e., when one feels confident of accomplishing a chosen or assigned task.

3. Meaningful Life: Inquiry into the Meaningful Life, or "life of affiliation", questions how individuals derive a positive sense of well-being, belonging, meaning, and purpose from being part of and contributing back to something larger and more permanent than themselves (e.g., nature, social groups, organizations, movements, traditions, belief systems).

\section{PERMA}

In Flourish (2011) Seligman argued that the last category of his proposed three kinds of a happy life, "meaningful life", can be considered as 3 different categories. The resulting acronym is PERMA: Positive Emotions, Engagement, Relationships, Meaning and purpose, and Accomplishments. It is a mnemonic for the five elements of Martin Seligman's well-being theory:

Positive emotions include a wide range of feelings, not just happiness and joy Included are emotions like excitement, satisfaction, pride and awe, amongst others. These emotions are frequently seen as connected to positive outcomes, such as longer life and healthier social relationships 
RJPSS Sept. 2020 Vol. XLV No.2, ISSN: (P)0258-1701 (e)2454-3403 Impact Factor: 7.717 https://doi.org/10.31995/rjpss.2020.v45i01.023

Engagement refers to involvement in activities that draws and builds upon one's interests. Mihaly Csikszentmihalyi explains true engagement as flow, a state of deep effortless involvement feeling of intensity that leads to a sense of ecstasy and clarity. The task being done needs to call upon higher skill and be a bit difficult and challenging yet still possible. Engagement involves passion for and concentration on the task at hand and is assessed subjectively as to whether the person engaged was completely absorbed, losing self-consciousness.

Relationships are essential in fueling positive emotions whether they are work-related, familial, romantic, or platonic. As Christopher Peterson puts it simply, "Other people matter Humans receive, share, and spread positivity to others through relationships. They are important not only in bad times, but good times as well. In fact, relationships can be strengthened by reacting to one another positively. It is typical that most positive things take place in the presence of other people.

Meaning is also known as purpose, and prompts the question of "why". Discovering and figuring out a clear "why" puts everything into context from work to relationships to other parts of life Finding meaning is learning that there is something greater than one's self. Despite potential challenges, working with meaning drives people to continue striving for a desirable goal.

Accomplishments are the pursuit of success and mastery. Unlike the other parts of PERMA, they are sometimes pursued even when accomplishments do not result in positive emotions, meaning, or relationships. That being noted, accomplishments can activate the other elements of PERMA, such as pride, under positive emotion. Accomplishments can be individual or community-based, fun- or work-based.

Each of the five PERMA elements was selected according to three criteria:

1. It contributes to well-being.

2. It is pursued for its own sake.

3. It is defined and measured independently of the other elements.

\section{Character Strengths and Virtues}

The development of the Character Strengths and Virtues (CSV) handbook (2004) represented the first attempt by Seligman and Peterson to identify and classify positive psychological traits of human beings. Much like the Diagnostic and Statistical Manual of Mental Disorders (DSM) of general psychology, the CSV provided a theoretical framework to assist in understanding strengths and virtues and for developing practical applications for positive psychology. This manual identified 6 classes of virtues (i.e., "core virtues"), underlying 24 measurable character strengths. 
Dr. Shaifali Agarwal

The CSV suggested these 6 virtues have a historical basis in the vast majority of cultures; in addition, these virtues and strengths can lead to increased happiness when built upon. Notwithstanding numerous cautions and caveats, this suggestion of universality hints threefold: 1 . The study of positive human qualities broadens the scope of psychological research to include mental wellness, 2. the leaders of the positive psychology movement are challenging moral relativism, suggesting people are "evolutionarily predisposed" toward certain virtues, and 3. virtue has a biological basis.

The organization of the 6 virtues and 24 strengths is as follows:

1. Wisdom and knowledge: creativity, curiosity, open-mindedness, love of learning, perspective, innovation

2. Courage: bravery, persistence, integrity, vitality, zest

3. Humanity: love, kindness, social intelligence

4. Justice: citizenship, fairness, leadership

5. Temperance: forgiveness and mercy, humility, prudence, self control

6. Transcendence: appreciation of beauty and excellence, gratitude, hope, humor, spirituality

Recent research challenged the need for 6 virtues. Instead, researchers suggested the 24 strengths are more accurately grouped into just 3 or 4 categories: Intellectual Strengths, Interpersonal Strengths, and Temperance Strengths] or alternatively, Interpersonal Strengths, Fortitude, Vitality, and CautiousnessThese strengths, and their classifications, have emerged independently elsewhere in literature on values. Paul Thagard described examples; these included Jeff Shrager's workshops to discover the habits of highly creative people Some research indicates that wellbeing effects that appear to be due to spirituality are actually better described as due to virtue

\section{Flow}

In the 1970s Csikszentmihalyi's began studying flow, a state of absorption where one's abilities are well-matched to the demands at-hand. Flow is characterized by intense concentration, loss of self-awareness, a feeling of being perfectly challenged (neither bored nor overwhelmed), and a sense that "time is flying". Flow is intrinsically rewarding; it can also assist in the achievement of goals (e.g., winning a game) or improving skills (e.g., becoming a better chess player). Anyone can experience flow, in different domains, such as play, creativity, and work. Flow is achieved when the challenge of the situation meets one's personal abilities. A mismatch of challenge for someone of low skills results in a state of anxiety; insufficient challenge for someone highly skilled results in boredom. 
RJPSS Sept. 2020 Vol. XLV No.2, ISSN: (P)0258-1701 (e)2454-3403 Impact Factor: 7.717

https://doi.org/10.31995/rjpss.2020.v45i01.023

\section{Research in positive psychology}

Research in positive psychology, well-being, eudaimonia and happiness, and the theories of Diener, Ryff, Keyes and Seligman cover a broad range of topics including "the biological, personal, relational, institutional, cultural, and global dimensions of life".A meta-analysis on 49 studies in 2009 showed that Positive Psychology Interventions (PPI) produced improvements in well-being and lower depression levels, the PPIs studied included writing gratitude letters, learning optimistic thinking, replaying positive life experiences and socializing with others. In a later meta-analysis of 39 studies with 6,139 participants in 2012, the outcomes were positive. Three to six months after a PPI the effects for subjective well-being and psychological wellbeing were still significant. However the positive effect was weaker than in the 2009 meta analysis, the authors concluded that this was because they only used higher quality studies. The PPIs they considered included counting blessings, kindness practices, making personal goals, showing gratitude and focusing on personal strengths Another review of PPIs published in 2018 found that over $78 \%$ of intervention studies were conducted in Western countries.

Ilona Boniwell, in her book Positive Psychology in a Nutshell, provided the following summary of the current research. Wellbeing is related to optimism, extraversion, social connections (i.e. close friendships), being married, having engaging work, religion or spirituality, leisure, good sleep and exercise, social class (through lifestyle differences and better coping methods) and subjective health (what you think about your health). Wellbeing is not related to age, physical attractiveness, money (once basic needs are met), gender (women are more often depressed but also more often joyful), educational level, having children (although they add meaning to life), moving to a sunnier climate, crime prevention, housing and objective health (what doctors say)

Sonja Lyubomirsky, in her book The How Of Happiness, says that to improve happiness individuals should create new habits; they can seek out new emotions, use variety and timing to prevent hedonic adaptation and enlist others to motivate and support during the creation of those new habits Lyubomirsky gives 12 happiness activities such as savouring life, learning to forgive and living in the present, each of which could become the basis for a new habit.

In Positive Psychology: The Science of Happiness, the authors Compton and Hoffman give the "Top Down Predictors" of wellbeing as high self esteem, optimism, self efficacy, a sense of meaning in life and positive relationships with others. The personality traits most associated with well being are extraversion, agreeability and low levels of neuroticism 
In the Journal of Occupational Rehabilitation, Kreutzer and Mills argue for the principles of positive psychology to be implemented to assist those recovering from traumatic brain injury (TBR). They make the case that TBI rehabilitation practices rely on the betterment of the individual through engaging in everyday practices, a practice significantly related to tenets of positive psychology Their proposal to connect positive psychology with TBI vocational rehabilitation (VR) also looks at happiness and its correlation with improvements in mental health, including increased confidence and productivity, as well as others While the authors point out that empirical evidence for positive psychology is limited, they clarify that positive psychology's focus on small successes, optimism and prosocial behaviour is promising for improvements in the social and emotional well-being of TBI patients.

\section{Conclusion}

Positive psychology is basically concerned with positive aspects of individual life. It works on both individual and societal life. Positive psychology is concerned with eudaimonia, "the good life" or flourishing, living according to what holds the greatest value in life. It has various benefits in humans life. Positive psychology teaches how to harness the power of shifting one's perspective to maximize the potential for happiness in many of our everyday behaviors. Another broad benefit of the positive psychology movement is a more well-defined idea of what "the good life" is.

\section{References}

1. Positive Psychology In a Nutshell: The Science of Happiness (3rd edition). London: Mc Graw Hill

2. www.wikipedia.com

3. Handbook of positive psychology by C. R. Snyder

4. Positive Psychology by Alan Carr

5. en.wikipedia.org

6. positivepsychology.com

7. psytreasure.com

8. amedleyofpotpourri.blogspot.com

9. ppac.sas.upen.edu

10. eslkevin.wordpress.com

11. wishtank.com

12. psychologistpretoriaeast.co.za

13. continuingcreation.org

14. brookspsychology.files.wordpress.com 